\title{
Seasonal variation in carbon monoxide poisoning in urban Korea
}

\author{
YOON SHIN KIM
}

From the Department of Environmental Sciences, School of Public Health, University of Texas, Houston, Texas 77225, USA

SUMMARY Seasonal variation in carbon monoxide (CO) poisoning during 1969-78 was examined using the monthly hospital admissions and environmental weather data from Seoul, Korea. The results showed that there were nine times as many cases of $\mathrm{CO}$ poisoning in December as in August. CO poisoning cases were significantly correlated with temperature and domestic fires but not significantly with relative humidity. The epidemiological and clinical investigation of $\mathrm{CO}$ poisoning in the home needs to be studied in further detail.

Accidental poisoning due to inhalation of carbon monoxide (CO) in the home has been a frequent social problem in Korea since the coal briquette called Yeontan has been used as a major domestic fuel for heating and cooking since the 1960s.'

CO poisoning has also been one of the major causes of fatal accidents in Korea. ${ }^{2}$ Over 3000 deaths from $\mathrm{CO}$ poisoning were reported in Korea in the period 1965-76 out of a total of 4304 persons intoxicated with $\mathrm{CO}^{3}$ About one million people have suffered from the noxious coal briquette exhaust, especially from $\mathrm{CO}$, during the same period.

A number of Korean studies have presented evidence for the severity of health hazards from $\mathrm{CO}$ poisoning in the home, ${ }^{4-6}$ but less effort has been directed towards investigating seasonal variation in $\mathrm{CO}$ poisoning and a correlation between seasonal $\mathrm{CO}$ poisoning and the corresponding environmental weather.

The present study was undertaken to examine the seasonal variation in cases of $\mathrm{CO}$ poisoning, particularly with regard to the influence of two selected meteorological parameters such as ambient temperature and relative humidity.

\section{Materials and methods}

All CO poisoning cases and meteorological data used in the study were monthly values from the 10-year period, totalling 120 months from January 1969 through December 1978. The data on $\mathrm{CO}$ poisoning cases presented here are based on daily records of admissions to Seoul National University Hospital's emergency room for treatment of $\mathrm{CO}$ intoxication during the same period. All $\mathrm{CO}$ poisoning cases were calculated on the basis of a 31-day month and expressed as a percentage variation about a monthly mean. The data on monthly mean temperature and relative humidity in Seoul during 1969-78 were obtained from the Annual Report of the Central Meteorological Office. ${ }^{7}$

In an attempt to determine the relation between CO poisoning cases and environmental weather, correlation analyses were performed for each of the four seasons separately. Then, in order to examine the influence of meteorology on the $\mathrm{CO}$ poisoning cases, regression of the monthly mean $\mathrm{CO}$ poisoning cases was calculated for the combined two meteorological parameters.

\section{Results}

Figure 1 shows a time series plot for the monthly values of $\mathrm{CO}$ poisoning cases and meteorological variables throughout the 10 -year period. Although the $\mathrm{CO}$ poisoning cases are limited to hospital admissions, these cases show a repeating seasonal pattern over the years.

Figure 2 shows the seasonal variation in the monthly cases of $\mathrm{CO}$ poisoning ranging from $23 \%$ to $201 \%$ of the monthly mean. The pattern of seasonal variation shows a peak in the winter months with a secondary rise in the autumn. The peak of the monthly variation also occurs in December but is approximately nine times greater than the corresponding variation in August.

The table shows correlation coefficients between $\mathrm{CO}$ poisoning cases and meteorological variables. The total number of $\mathrm{CO}$ poisoning cases showed 79 
$(\mathrm{r}=-0.63 ; \mathrm{p}<0.001)$ but weak and not significant correlation with relative humidity $(r=-0 \cdot 27)$. The correlation between $\mathrm{CO}$ poisoning cases and temperature was significant for both summer $(\mathrm{r}=-0.55 ; \mathrm{p}<0.001)$ and autumn $(\mathrm{r}=-0.67$; $\mathrm{p}<0.001)$.
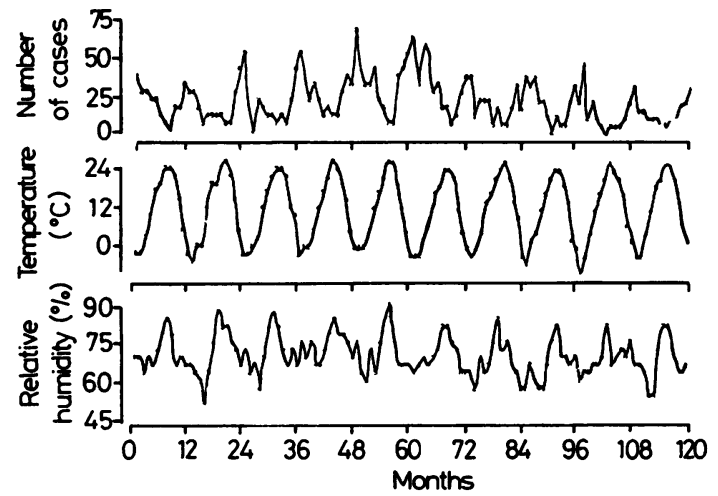

Fig 1 Plot of (a) monthly $\mathrm{CO}$ poisoning cases and of monthly mean weather parameters; (b) temperature; (c) relative humidity between January 1969 and December 1978.

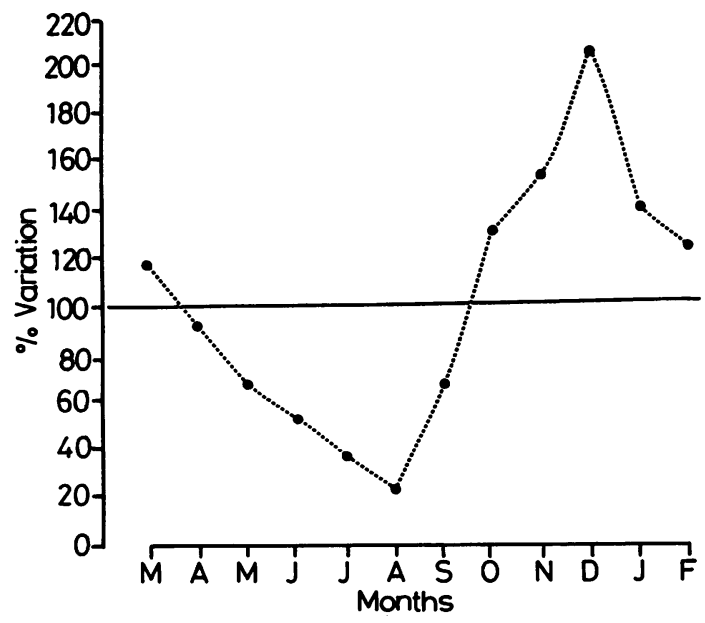

Fig 2 Monthly variation in $\mathrm{CO}$ poisoning admissions to Seoul National University Hospital, 1969-78.

Table 1 Correlation coefficients between $\mathrm{CO}$ poisoning cases and weather parameters according to season

\begin{tabular}{lccccc}
\hline Weather & Spring & Summer & Autumn & Winter & Total \\
\hline Temperature $\left({ }^{\circ} \mathrm{C}\right)$ & -0.367 & $-0.552^{*}$ & $-0.672^{*}$ & 0.012 & $-0.632^{*}$ \\
Relative humidity $(\%)$ & 0.476 & -0.068 & -0.138 & 0.077 & -0.265 \\
\hline
\end{tabular}

${ }^{*} \mathrm{p}<0.001$.
A linear multivariate regression model expressed by equation 3 was compared with the single regression model of equations 1 and 2 to estimate the effects of meteorological parameters on the $\mathrm{CO}$ poisoning cases.

$$
\begin{aligned}
\mathrm{CO}= & 29.777-0.885(\mathrm{TEMP}) & & \ldots . .(1) \\
& (1.532)(0 \cdot 100) & \mathrm{R}^{2}=0.400 & \\
\mathrm{CO}= & 52.814-0.481(\mathrm{RH}) & & \ldots .(2) \\
& (11.238)(0 \cdot 161) & \mathrm{R}^{2}=0.070 & \\
\mathrm{CO}= & 8.042-1.044(\mathrm{TEMP})+ & 0.340(\mathrm{RH}) & \ldots . .(3) \\
& (10.359)(0 \cdot 124) & (0.160) \mathrm{R}^{2}= & 0.422
\end{aligned}
$$

The figures in parentheses are standard errors of the estimates. The combined meteorological parameters in equation 3 explain more than $42 \%$ of the total variations in $\mathrm{CO}$ poisoning cases while each meteorological parameter in equations 1 and 2 accounts for $40 \%$ and $7 \%$ of the total variations, respectively. This analysis shows that equations 1 and 3 were significant $(p<0.01)$, and $F$ values by analysis of variance were 78.658 and 42.744 respectively, while the $F$ value in equation 2 was not significant

\section{Discussion}

The present study based on hospital data shows that the incidence of $\mathrm{CO}$ poisoning cases is correlated significantly with temperature but not significantly with relative humidity. The regression results also confirm a strong correlation between $\mathrm{CO}$ poisoning and temperature which accounts for the total? variation in $\mathrm{CO}$ poisoning.

There was a close correlation between $\mathrm{CO}$ poisoning and temperature for the summer months, and this association was much stronger in August particularly when the temperature was high. This relation between $\mathrm{CO}$ poisoning and temperature may be considered in line with those of weather and the use of Yeontan.

About $70 \%$ of households in Korea still use Yeontan as domestic fuel for heating and cooking. ${ }^{8} \mathrm{~A}$ very unique underfloor heating system called Ondol has traditionally been used in Korea. In these circumstances, $\mathrm{CO}$ poisoning in the home may occur unless Koreans use the coal briquette or keep the traditional heating system.

There have been many studies of the epidemiology and clinical application of $\mathrm{CO}$ poisoning in Korea. ${ }^{4-69}$ Despite the effort to prevent $\mathrm{CO}$ poisoning in homes throughout the nation, there still remain gaps in knowledge about it.

Factors other than meteorological effects which could influence the seasonal pattern of $\mathrm{CO}$ poisoning are likely to include the type of socioeconomic environment. $\mathrm{CO}$ poisoning in homes can be of special interest in terms of indoor $\mathrm{CO}$ pollution. 
A study is planned to investigate the indoor concentrations of $\mathrm{CO}$ in homes in the future. Also, a further study of the actual household exposure to $\mathrm{CO}$ under real conditions should be conducted to assess possible health consequences of $\mathrm{CO}$ poisoning.

\section{References}

${ }^{1}$ Yun DR. Various aspects of carbon monoxide poisoning. J Kor Med Assoc 1965; 8: 72-5. (In Korean).

${ }^{2}$ Korea Bureau of Statistics. Mortality by cause of death in 1979. Seoul: KEPB, 1980.

${ }^{3}$ Lee OH. Review on carbon monoxide poisoning in Korea. Kor J Environ Health Soc 1978; 5: 25-39. (In Korean).
${ }^{4} \mathrm{Bin}$ SD. Epidemiology of briquette gas poisoning. $J$ Kor Med Assoc 1968; 11: 863-8. (In Korean).

${ }^{5}$ Kim YI, Cho SH, Kim JS, Yun DR, Kim ID. An epidemiological study on carbon monoxide poisoning in urban slum areas. $J$ Kor Med Assoc 1980; 23: 879-87. (In Korean).

${ }^{6}$ Yun DR, Cho SH. A study of the incidence and therapeutic measures on carbon monoxide poisoning in Seoul.J Kor Med Assoc 1977; 20: 705-13. (In Korean).

${ }^{7}$ Korea Central Meteorological Office. Annual report of the central meteorological office, 1969-78. Seoul: CMO, 1971-80.

${ }^{8}$ Korea Bureau of Statistics. Population and housing census of 1975. Seoul: KEPB, 1977.

${ }^{9}$ Yun DR, Cho SH. Hyperbaric oxygen treatment-basic principles and clinical applications. Seoul J Med 1980; 21: 219-29. (In Korean). 